\title{
NUMERICAL MODELLING AND SIMULATION OF VEHICULAR IMPACTS ON TIRE-MOUNTED CABLE BARRIERS
}

\author{
HOWIE FANG ${ }^{*} \&$ AMEY BADAR \\ The University of North Carolina at Charlotte, USA
}

\begin{abstract}
This research focused on evaluating retrofit designs for cable barriers using reclaimed tires so as to reduce the chance of vehicle under-riding for small passenger cars. Finite element (FE) analysis was used to conduct simulations of full-scale vehicular crashes into these retrofit cable barriers and the barriers' performance was evaluated. Four designs of the tire-mounted cable barriers were modelled and evaluated under impacts by a 1996 Dodge Neon, which was in compliance with the 1100C test vehicle specified by the Manual for Assessing Safety Hardware (MASH). Ten different material models were used in the FE models, including the piecewise linear plasticity model for steel components, elastic model for the tires and a few other components, viscous damping model for the shock absorbers, lowdensity foam model for the radiator core, spot-weld model for sheet metal connections, Blatz-Ko rubber model for rubber cushions, rigid model for most mounting hardware, and null material model defined for contact purposes. The simulations of vehicular crashes were conducted on both a flat terrain and a sloped median. The impact conditions were based on the MASH Test Level 3 (TL-3) requirements, i.e., at an impact speed of $100 \mathrm{~km} / \mathrm{h}(62.1 \mathrm{mph})$ and a $25^{\circ}$ impact angle. The simulation results showed that the tire-mounted cable barrier could improve the safety performance of the current cable barrier system (i.e., without tires) under impacts of small passenger cars.
\end{abstract}

Keywords: finite element, modelling, simulation, impact, contact, cable barrier, tire mounted.

\section{INTRODUCTION}

Roadside barriers are used on highways to prevent errant vehicles from entering dangerous areas such as steep slopes, rocks, or oncoming traffic. Roadside barriers can be categorized based on their overall rigidity as flexible barriers (such as cable barriers), semi-rigid barriers (such as W-beam and Thrie-beam guardrails), and rigid barriers (such as concrete barriers). Cable barriers are typically installed on highway medians and generally cause less severe damage and injuries to the striking vehicles and occupants than W-beam guardrails and concrete barriers. However, cable barriers require the median to have sufficient width to accommodate cable deflections in the transverse direction.

In 1967, Graham et al. developed four mathematical models for predicting the trajectory of a vehicle in collision with cable median barriers (CMBs) and W-beam guardrails [1]. The research included vehicle speeds up to $97 \mathrm{~km} / \mathrm{h}(60 \mathrm{mph})$ and impact angles up to 35 degrees to represent the worst-case scenario of highway accidents. Based on suggestions from this research, New York State adopted a standard barrier height of $0.762 \mathrm{~m}$ (30 inches) with a $0.076 \mathrm{~m}$ (3 inch) cable spacing and a $4.88 \mathrm{~m}$ (16 foot) post spacing. In 1990, Phillips et al. studied the performance of terminal ends of cable barriers in crash events [2]. Twelve fullscale tests were conducted in accordance with the NCHRP report 230 to evaluate three distinct terminal designs. It was concluded that the terminal used in the standard CMB could snag and overturn the vehicle in an impact and a new terminal design demonstrated acceptable characteristics was developed. In 1993, Laker et al. studied a new cable barrier design to overcome the deficiencies of an earlier two-cable system [3]. The new design,

*ORCID: http://orcid.org/0000-0002-3483-0374 
which included a second pair of ropes added to the slots on the $6 \mathrm{~mm}$ gauge steel posts, were crash tested and found to meet the standards by the UK Department for Highways. Also in 1993, Yang et al. investigated the causes of tension loss in cable barriers and developed corrective measures for the same [4]. This study used laboratory tests on normal and prestressed cables to determine if there were any significant differences in cable strain due to long term loading. In 1997, Hunter et al. evaluated the in-service performance of three-strand CMBs on interstate highways [5]. Based on crash data collected from 1990 to 1997, several regression models were developed and used to estimate the effects of CMB installation on crash rates. The study showed that, while the number of crashes was increased due to CMB installations, the number of fatal crashes and head-on collisions and the overall severity indices were greatly reduced.

In 1998, Sposito and Johnston studied the effectiveness of the three-strand CMBs in preventing crossover accidents on interstate and evaluated the maintenance and repair costs [6]. They found out that CMBs were cost effective compared to the concrete barriers and that CMBs worked the best in medians with a minimum of $7 \mathrm{~m}$ width. In the work by Cooner et al., they evaluated the in-service performance of various proprietary CMBs in Texas [7]. It was found from the study that the overall fatalities caused by cross-over crashes were significantly reduced since the installation of the CMBs. In 2013, Stolle and Sicking investigated $\mathrm{CMB}$ containment failures and crash severity and found that low-tension CMBs had lower, crash severity rate but higher penetration and rollover rates than high-tension CMBs [8]. In 2014, Stolle studied the contributing factors to CMB penetrations [9]. They found that high-tension CMBs experienced overriding due to cable entrapment by the posts and that low-tension CMBs experienced under-riding penetrations due to the low strength of connections to attached bottom and middle cables to the post. The study by Burns and Bell on $\mathrm{CMB}$ performance showed that while crash occurrence was increased following the installation of CMBs, the number of fatal crashes and head-on collisions were reduced by a significant amount [10].

Besides evaluation of in-service CMBs, modelling and simulation work were also conducted on CMB performance evaluations. In 2005, Hiser and Reid developed improved methods for modelling slip base structures in impact analysis [11]. In 2007, Marzougui et al. conducted a study using finite element (FE) and vehicle dynamics analysis on the effect of sloped terrain to CMB performance [12]. The FE models were validated with full-scale crash testing data and the simulation results showed that, when installed on flat terrain, the CMB studied met the safety requirement of NCHRP Report 350. On a 6:1 sloped median, the simulation results showed that the CMB could redirect a pickup truck with the CMB at an

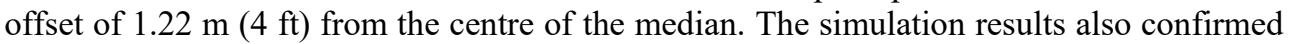
the observation from full-scale crash test that the CMB might not redirect mid-size and small vehicles if the CMB was placed more than $0.3 \mathrm{~m}(1 \mathrm{ft})$ from centre of the median. In 2010, Mohan et al. developed and validate the FE model of a 3-strand CMB that included details of the soil, posts, cables, and hook bolts [13]. Fang et al. developed full-scale FE models of North Carolina CMBs on a sloped median and evaluated their performance at various impact speeds and angles [14]. A new retrofit design was developed in the study and was found to have improved performance of the current CMB design. Subsequently, Fang et al. studied the performance of CMBs on sloped medians with horizontal curvatures [15]. In the work of Stolle and Reid, they developed a wire rope FE model for cable barriers and performed a mesh sensitivity analysis to determine the optimum mesh size with good accuracy and computational efficiency [16]. Stolle et al. used computer simulations to evaluate a new cable to post attachment for high tension cable barriers [17]. In 2013, Wang et al. studied the modelling of slender members in CMBs, such as hook bolts and cables [18]. It was found 
that the beam-element model outperformed those using solid and shell elements, in both accuracy and computational efficiency.

Since the 1970's, tires have been suggested for use in barriers to improve energy absorption in vehicular crashes, as seen in a number of patents [19]-[28]. However, few studies exist in literature on the performance of barrier systems designed or retrofitted with reclaimed tires. Although CMBs have been shown to be generally effective in preventing cross-median crashes, there still exists vehicle under-riding when impacted by some small passenger cars. In this study, nonlinear FE simulations were utilized to evaluate the performance of CMBs mounted with reclaimed tires. The goal of this research was to develop a retrofit $\mathrm{CMB}$ design with reclaimed tires that could prevent small passenger cars from under-riding. In the remaining portion of the paper, the FE models of a test vehicle and CMBs are first presented. The impact conditions based on the Manual for Assessing Safety Hardware (MASH) [29] were then introduced. Finally, the simulation results are analysed and discussed in detail, followed by some concluding remarks and recommendations for future work.

\section{MODELLING OF TEST VEHICLE AND CABLE BARRIERS}

\subsection{FE modelling of test vehicle}

The test vehicle was a 1996 Dodge Neon with a curb weight of 2,414 lb (1,095 kg). The FE model of this vehicle was originally developed for LS-DYNA [30] and validated using fullscale crash tests at the National Crash Analysis Centre, had a total of 339 parts composed of 283,683 nodes and 270,953 elements (2,852 solid, 92 beam, 267,775 shell, and 234 other elements). Ten different material models were used in the FE models, including the piecewise linear plasticity model for most steel components, elastic model for the tires and a few other components, viscous damping model for the shock absorbers, low-density foam model for the radiator core, spot-weld model for sheet metal connections, Blatz-Ko rubber model for rubber cushions, rigid model for most mounting hardware, and null material model defined for contact purposes. Hourglass control was used on various components that could potentially experience large deformations. The FE model of the 1996 Dodge Neon is shown in Fig. 1.

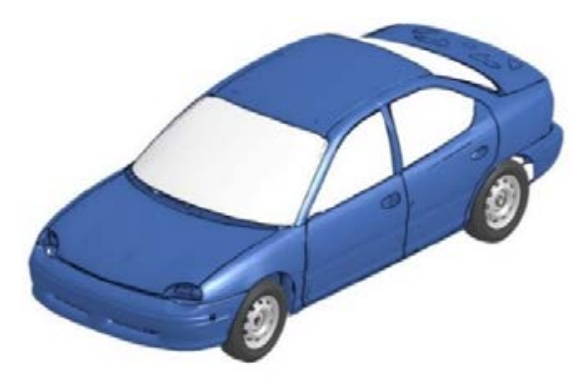

Figure 1: FE model of a 1996 Dodge Neon.

\subsection{Modelling of tire-mounted CMBs (TMCMBs)}

The FE model of the tire-mounted CMB (TMCMB) was created based on the NCDOT lowtension, three-cable CMB, as shown in Fig. 2 along with a real NCDOT CMB. 


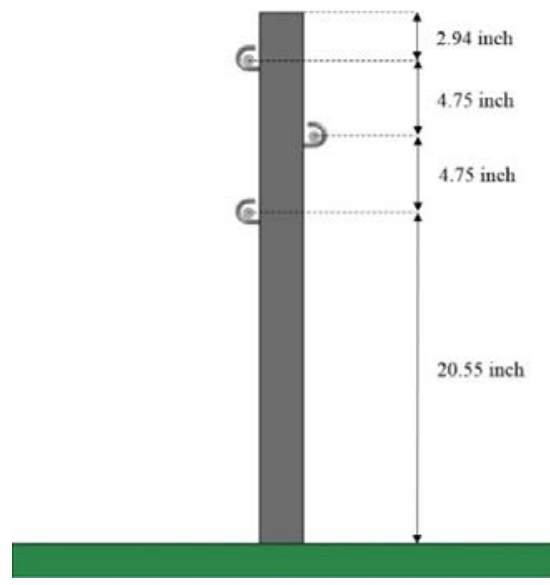

(a)

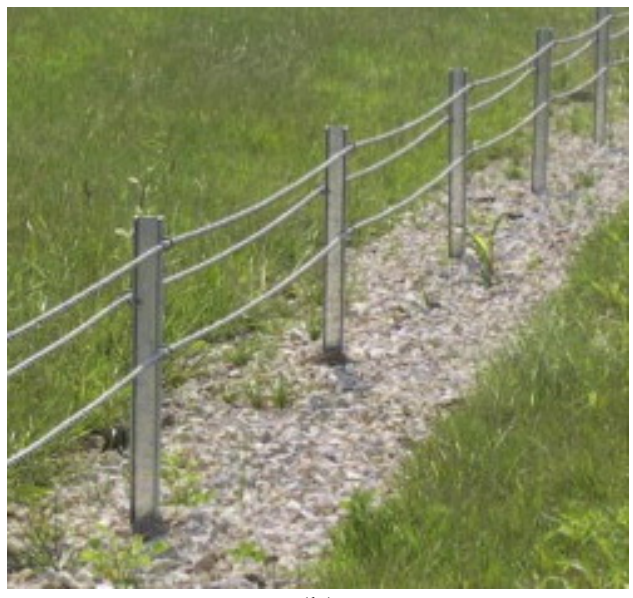

(b)

Figure 2: A cable median barrier. (a) FE model of the current NCDOT CMB; and (b) An NCDOT low-tension CMB.

The tire used to mount onto the CMB was a P245/70R17 tire from a 2007 Chevrolet Silverado. The FE model of the tire, as shown in Fig. 3(a), was composed of 4,380 shell elements with mesh sizes from $12-15 \mathrm{~mm}$ for both the tread and sidewall. The tire was modelled as elastic material with Young's modulus of 29.4 MPa and Poisson's ratio of 0.45. The thickness of the shell elements was kept uniform at $7.5 \mathrm{~mm}$ so that the total mass of the tire was $35 \mathrm{lb}(15.9 \mathrm{~kg})$. The tire was mounted to the two cables on the same side of the CMB, as schematically shown in Fig. 3(b).

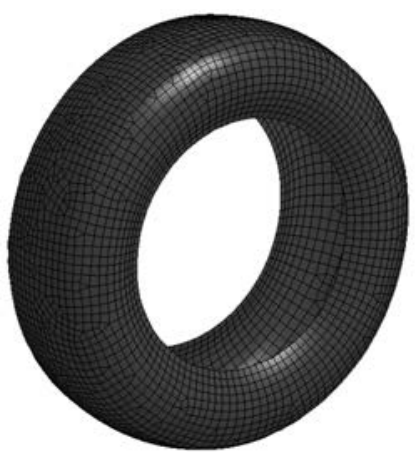

(a)

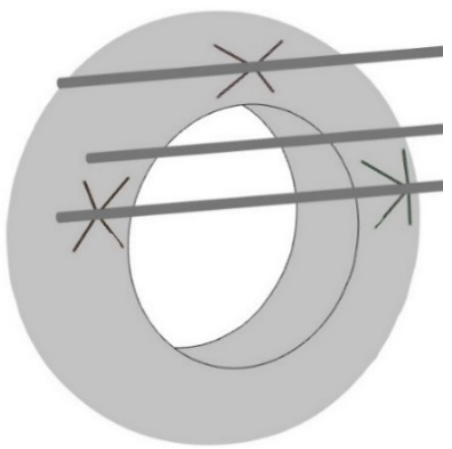

(b)

Figure 3: FE model of tire and tire mounting on CMBs. (a) FE model of a P245/70R17 tire; and (b) Tire mounting on CMB cables.

In this study, four TMCMB designs were evaluated on their performance in vehicle redirection and/or preventing vehicle under-riding. The four designs, as shown in Fig. 4, are named based on cable heights and hook types: original cable heights with J-hooks (TMCMBO-J), original cable heights with U-hooks (TMCMB-O-U), new cable heights witth J-hooks 
(TMCMB-N-J), and new cable heights witth U-hooks (TMCMB-N-U). It should be noted that the J-hooks, upon yielding, allow for cables to be released from the hooks, while the Uhooks will not allow the cables to be detached unless ultimate failure occurs on the U-hooks.

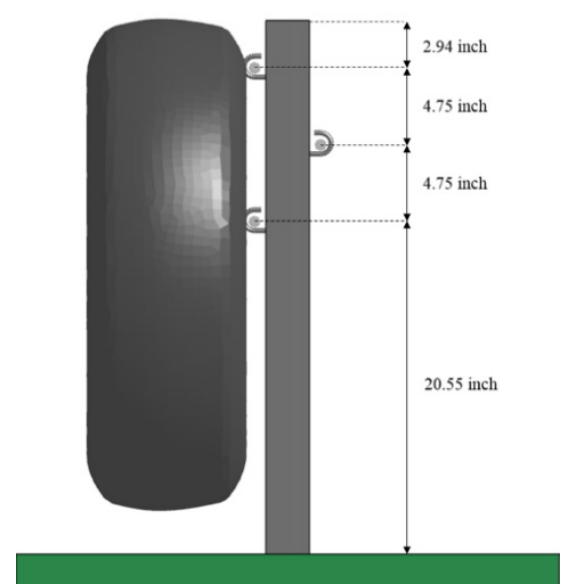

(a)

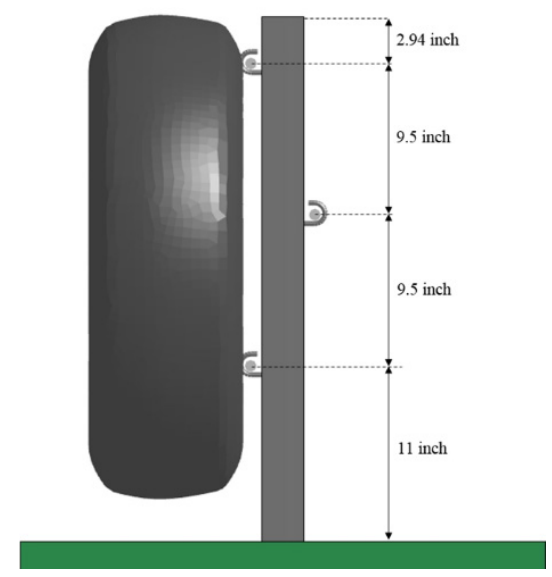

(c)

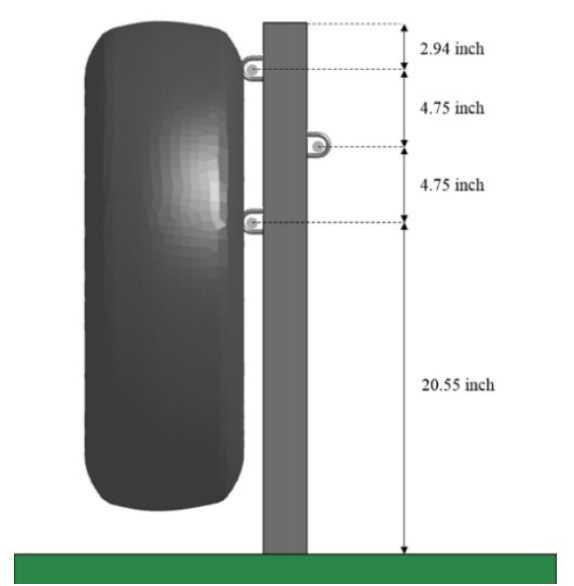

(b)

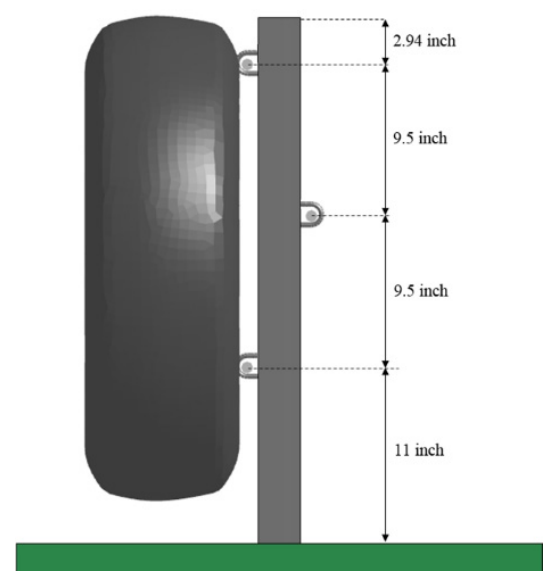

(d)

Figure 4: Four proposed designs to augment a CMB with reclaimed tires. (a) Design \#1: TMCMB-O-J; (b) Design \#2: TMCMB-O-U; (c) Design \#3: TMCMB-N-J; and (d) Design \#4: TMCMB-N-U.

In the FE models of TMCMBs, the tires were attached to the cables by rigid nodal bodies, and there were a total of six tires placed equidistantly between two posts.

\subsection{Simulation setup}

In this study, the four TMCMB designs were first evaluated using a $400 \mathrm{ft}(120 \mathrm{~m})$ section placed on a flat terrain and impacted by the vehicle from the side with the mounted tires. The best of the four TMCMB designs was then evaluated on a $6 \mathrm{H}: 1 \mathrm{~V}$ sloped median with two TMCMB placements (see Fig. 5), one on the slope where the vehicle would impact the tires 
on the barrier before reaching to the bottom of the ditch and the other on the slope where the vehicle would reach the bottom of ditch before impacting the tires on the barrier. For both TMCMB placements, the vehicle impacted the barrier from both front-side (i.e., the vehicle impacted the barrier before reaching the bottom of ditch) and backside (i.e., the vehicle reached the bottom of ditch before hitting the barrier).

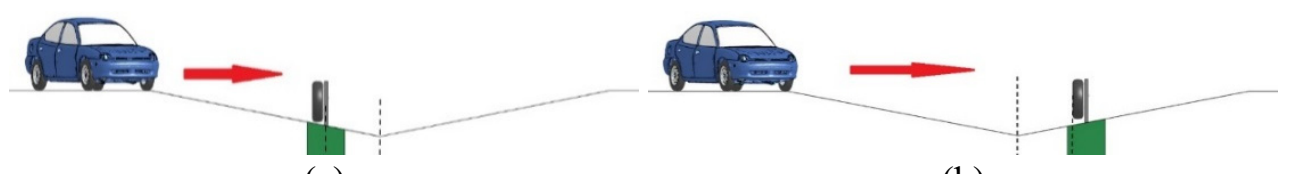

(a)

(b)

Figure 5: TMCMB placement on a $6 \mathrm{H}: 1 \mathrm{~V}$ sloped median. (a) Placement 1; and (b) Placement 2.

Crash simulations were performed under MASH TL-3 impact conditions, i.e., at a speed of $62.1 \mathrm{mph}(100 \mathrm{~km} / \mathrm{h})$ and an impact angle of 25 degrees. In all the simulations, the initial impact points were at the mid-point of two posts at mid-span of the TMCMB.

\section{PERFORMANCE EVALUATION OF TIRE-MOUNTED CABLE BARRIERS}

\subsection{Vehicular impacts on TMCMB placed on a flat terrain}

Numerical simulations were first conducted for vehicular impacts on the four TMCMBs placed on a flat terrain. The FE simulation results of vehicle trajectories' after impacting the TMCMBs are shown in Fig. 6 in which the barriers are shown in their undeformed shapes and the rectangular boxes in dashed lines give the exit boxes specified in MASH.

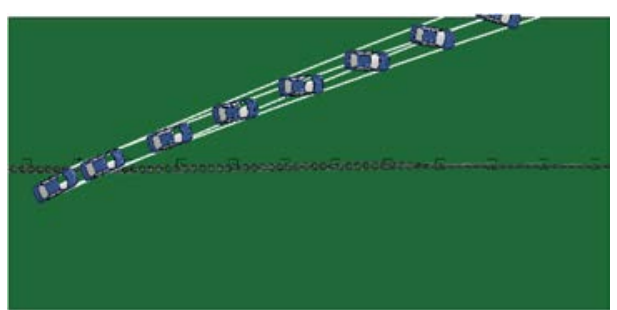

(a)

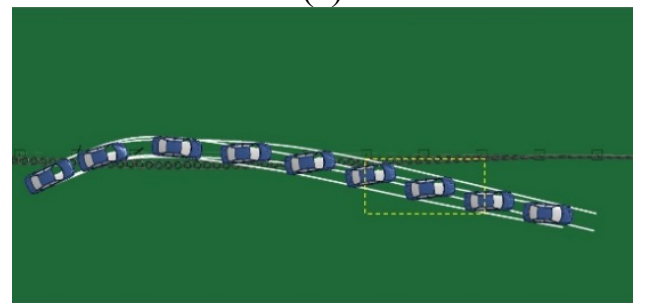

(c)

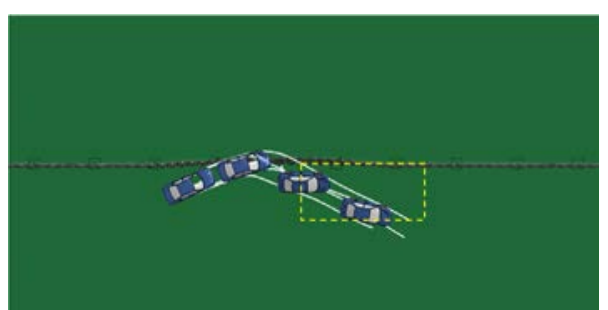

(b)

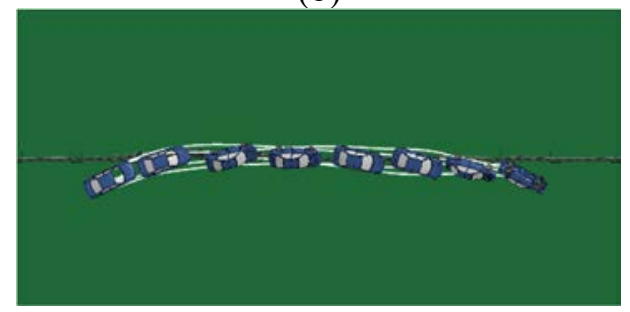

(d)

Figure 6: Vehicle trajectories after impacting the TMCMBs on a flat terrain. (a) Design \#1: TMCMB-O-J; (b) Design \#2: TMCMB-O-U; (c) Design \#1: TMCMB-N-J; and (d) Design \#2: TMCMB-N-U. 
In the case of TMCMB-O-J, the vehicle under-rode and penetrated the barrier since the cables were released from the J-hooks. This was considered a failed case because the vehicle entered into the oncoming travel lane. For the TMCMB-O-U design, the cables were not released due to the use of U-hooks and thus retained and redirected the vehicle. However, due to the rigidity of the TMCMB, the vehicle was bounced back and went out of the bottom side of the exit box, which was considered as a failed case by MASH. In the case of TMCMB_N_J, which used J-hooks but had lowered cables, the vehicle was successfully redirected and passed the MASH exit box criterion, i.e., leaving the exit box from the right side. Finally, in the case of TMCMB_N_U, the vehicle was redirected but rolled over towards the impacting side, which was also considered a failed case as per MASH. It should be noted that since the vehicle stayed in contact with TMCMB_N_U, the exit box criterion was not applicable according to MASH. Based on the above analysis, the TMCMB_N_J design was determined to outperform the other three proposed designs and was further evaluated on a sloped median, as presented next. Fig. 7 shows the front views of vehicle-barrier interactions for the case of TMCMB-N-J.
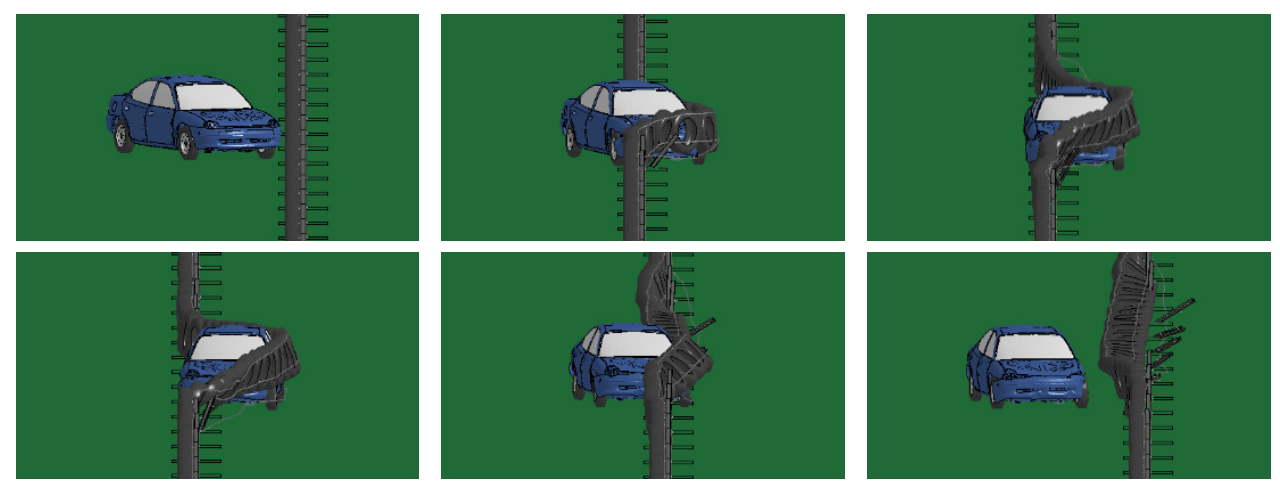

Figure 7: Vehicle-interactions for the TMCMB-N-J on a flat terrain.

\subsection{Vehicular impacts on TMCMB-N-J placed on a 6H:1V sloped median}

The TMCMB-N-J design was shown to outperform other designs on a flat terrain, which was the standard test site required by MASH. To evaluate its performance under in-service conditions, which is also recommended by MASH, the TMCMB-N-J design was tested on a $6 \mathrm{H}: 1 \mathrm{~V}$ sloped median with two TMCMB placements shown in Fig. 5. Full-scale FE simulations were performed for vehicular impacts from both front-side and backside of the TMCMB-N-J design and the simulation results are summarized in Table 1.

Fig. 8 shows the top view of vehicle trajectories for both front-side and backside impacts on the TMCMB-N-J for Placement 1 . The exit boxes defined by MASH are shown by the

Table 1: Simulation results of the TMCMB-N-J design place on a $6 \mathrm{H}: 1 \mathrm{~V}$ sloped median.

\begin{tabular}{lll}
\hline TMCMB placement & Impact side & Vehicular responses \\
\hline \multirow{2}{*}{ Placement 1} & Front & Redirected (exit box criterion satisfied) \\
\cline { 2 - 3 } & Back & Redirected (exit box criterion satisfied) \\
\hline \multirow{2}{*}{ Placement 2} & Front & Redirected (exit box criterion satisfied) \\
\cline { 2 - 3 } & Back & Redirected (exit box criterion not applicable) \\
\hline
\end{tabular}




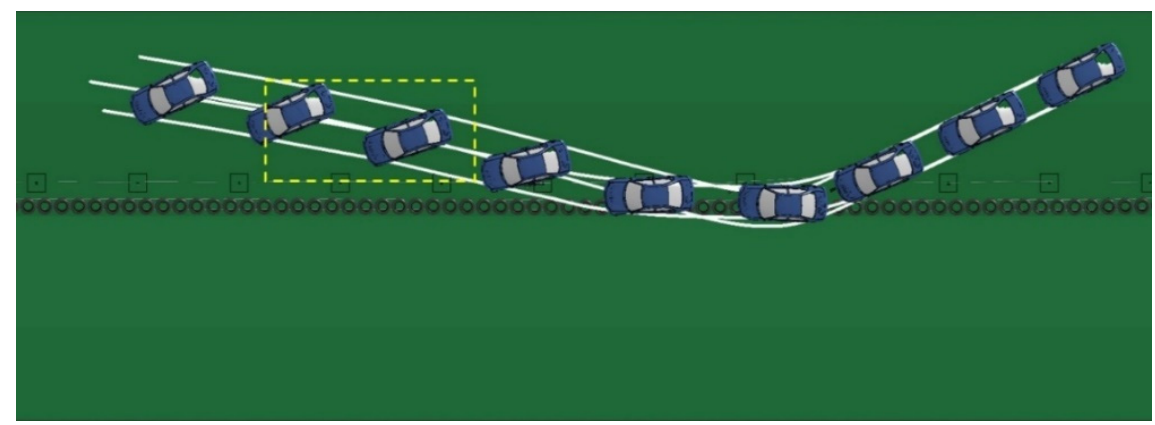

(a)

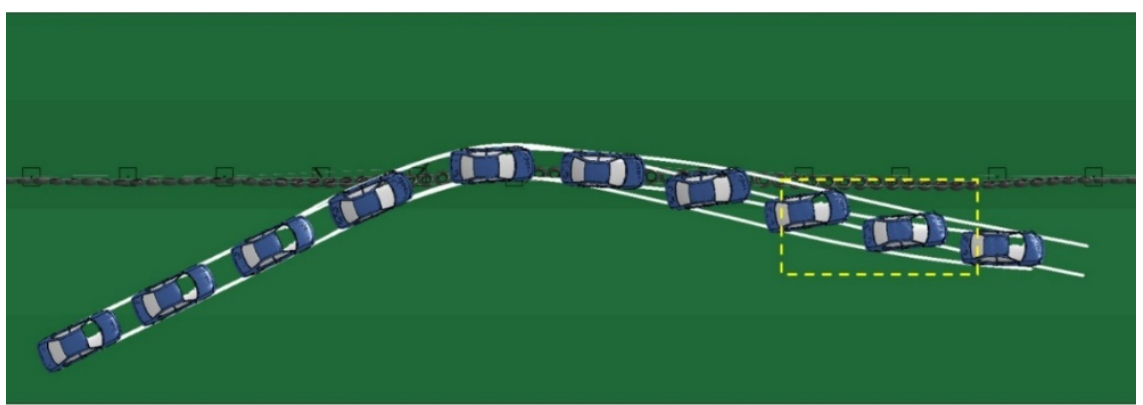

(b)

Figure 8: Dodge Neon impacting the TMCMB-N-J for Placement 1. (a) Front-side impact; and (b) Backside impact.

rectangles in dashed lines. It can be seen that the vehicle was redirected in both cases and the MASH exit box criterion was satisfied, i.e., the vehicle's tire marks were within the exit box before leaving the exit box from the exit side.

Fig. 9 shows the yaw, roll, and pitch angles of the Dodge Neon impacting the TMCMBN-J for Placement 1. For both front-side and backside impacts, the vehicle's roll and pitch

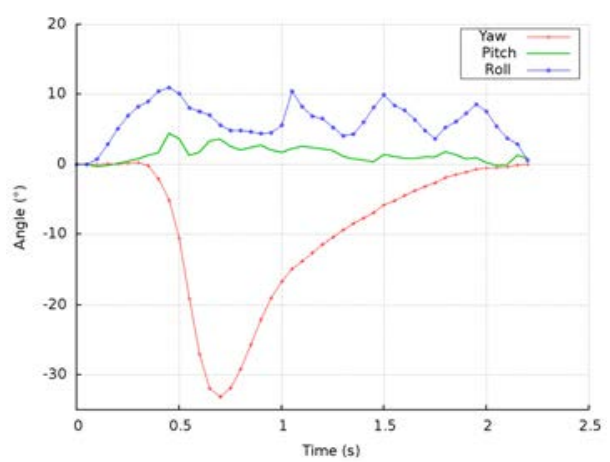

(a)

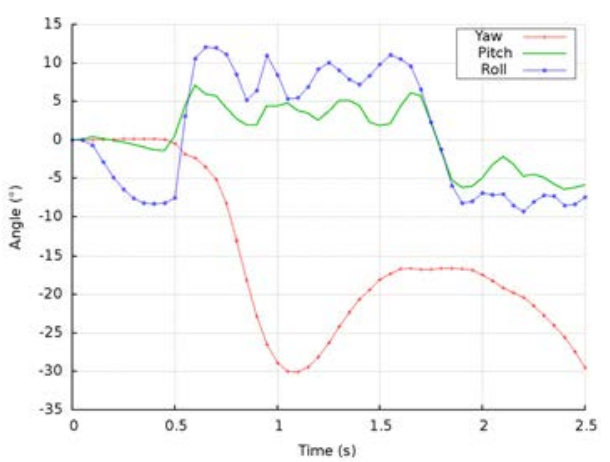

(b)

Figure 9: Yaw, pitch and roll angles of the Dodge Neon impacting the TMCMB-N-J for Placement 1. (a) Front-side impact; and (b) Backside impact. 
angles were less than $15^{\circ}$ in both positive and negative directions, and thus passed the MASH Criterion $F$, which specified a maximum of $75^{\circ}$ of roll or pitch angle. Fig. 10 shows the vehicle's transverse velocities towards the travel lane in the two impact cases shown in Fig. 8 . The vehicle's transverse velocities were approximately $10 \mathrm{~km} / \mathrm{h}$ after redirected, indicating a small likelihood of getting involved in a secondary collision.

Fig. 11 shows the top view of vehicle trajectories for both front-side and backside impacts on the TMCMB-N-J for Placement 2. It can be seen that the vehicle was redirected in both

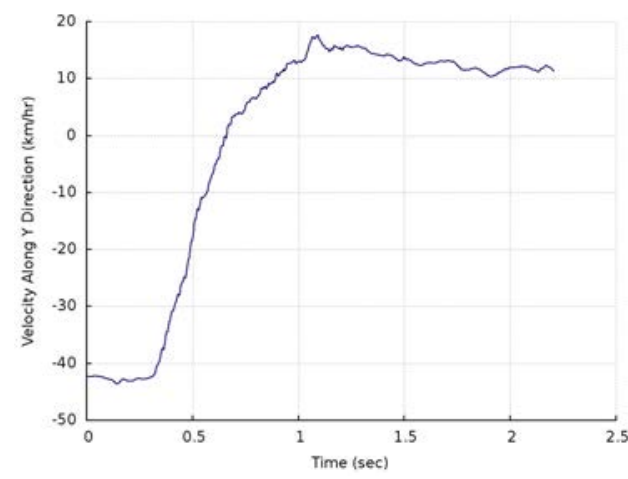

(a)

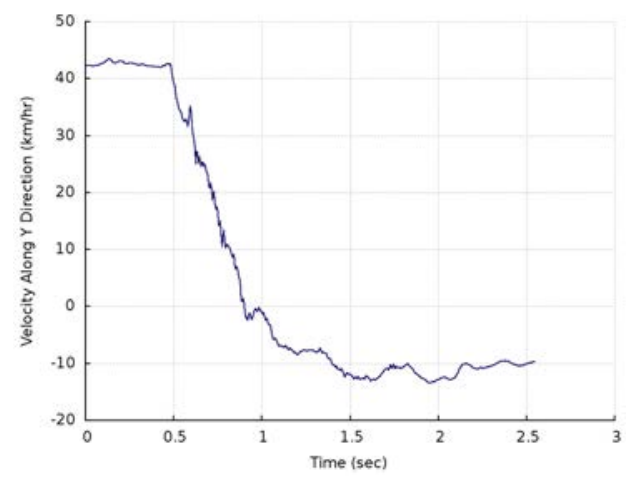

(b)

Figure 10: Transverse velocities of the Dodge Neon impacting the TMCMB-N-J for Placement 1. (a) Front-side impact; and (b) Backside impact.

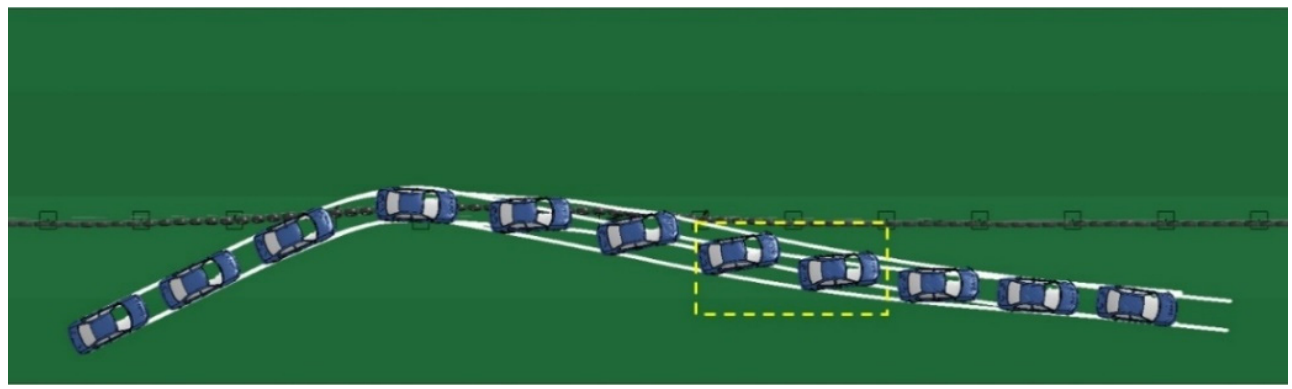

(a)

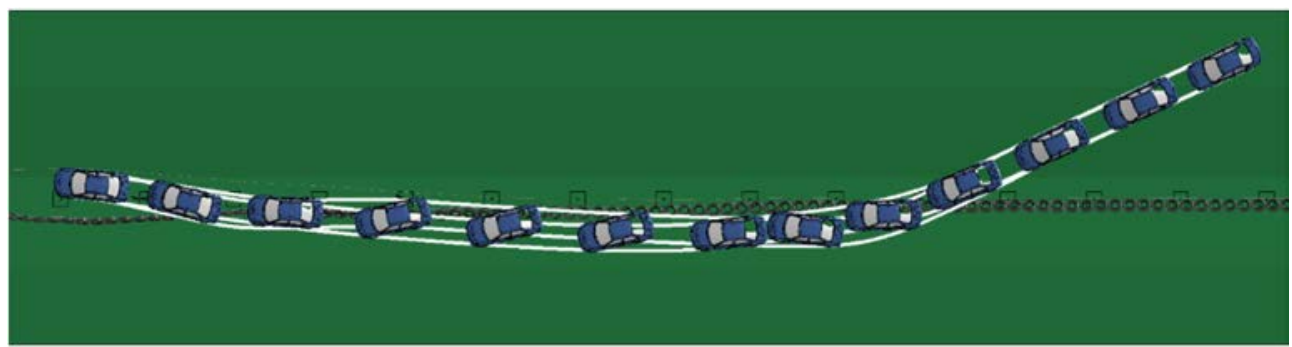

(b)

Figure 11: Dodge Neon impacting the TMCMB-N-J for Placement 2. (a) Front-side impact; and (b) Backside impact. 
cases and the MASH exit box criterion was satisfied for the case of front-side impact. For backside impact, the vehicle stayed in contact with the TMCMB after being redirected; therefore, the exit box criterion was not applicable according to MASH.

Fig. 12 shows the yaw, roll, and pitch angles of the Dodge Neon impacting the TMCMBN-J for Placement 2. For both front-side and backside impacts, the vehicle's roll and pitch angles were less than $15^{\circ}$ in both positive and negative directions, thus passing the MASH Criterion F. Fig. 13 shows the vehicle's transverse velocities towards the travel lane for both cases. The vehicle's transverse velocities were less than $10 \mathrm{~km} / \mathrm{h}$ after redirected, indicating a small likelihood of getting involved in a secondary collision.

The simulation results shown in Figs 8-13 indicated that the TMCMB-N-J design worked well when placed on a $6 \mathrm{H}: 1 \mathrm{~V}$ sloped median for both placements. The use of reclaimed tires to retrofit the $\mathrm{CMB}$ was shown to be effective in eliminating vehicle under-riding by small passenger cars such as the Dodge Neon, which was seen on the currently used CMB systems. It should be noted that the TMCMB-N-J design should also be tested under impacts by a

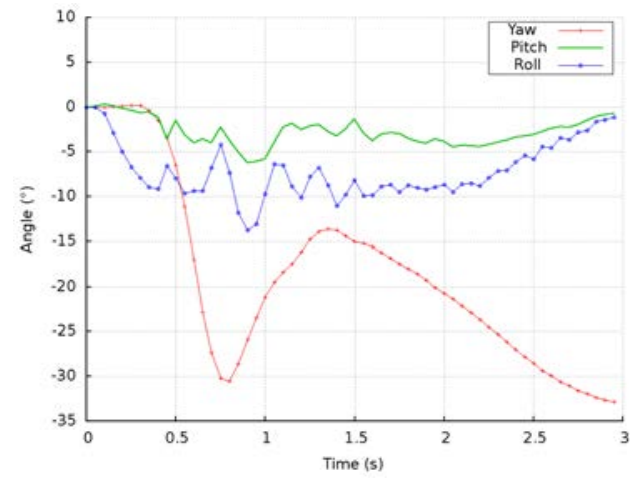

(a)

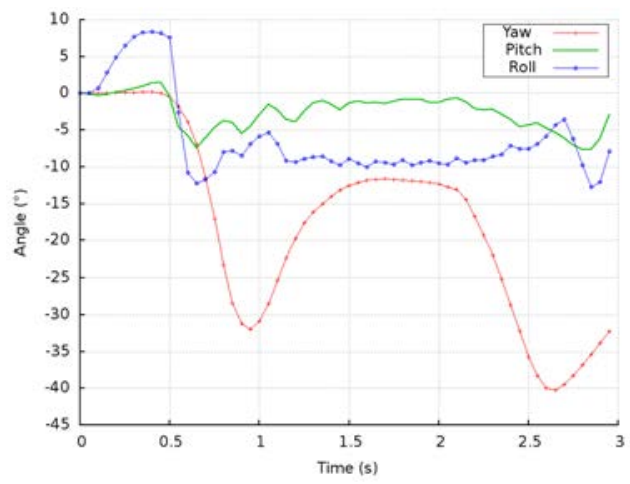

(b)

Figure 12: Yaw, pitch and roll angles of the Dodge Neon impacting the TMCMB-N-J for Placement 2. (a) Front-side impact; and (b) Backside impact.

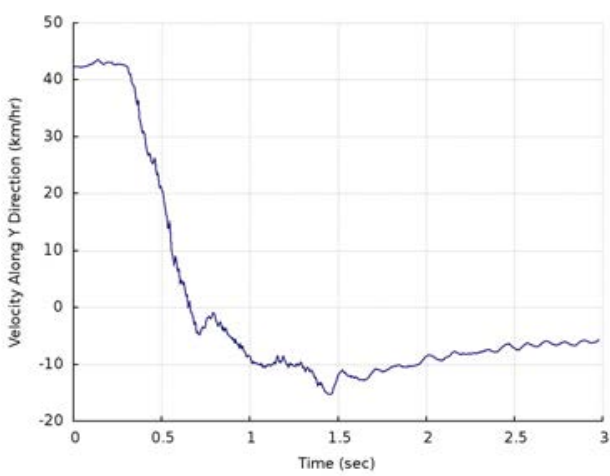

(a)

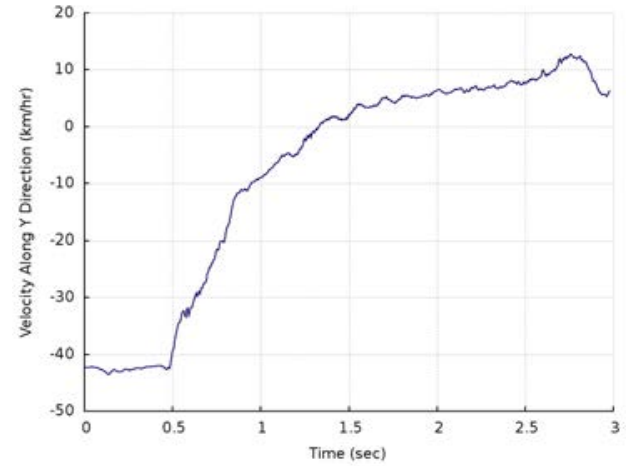

(b)

Figure 13: Transverse velocities of the Dodge Neon impacting the TMCMB-N-J for Placement 2. (a) Front-side impact; and (b) Backside impact. 
pickup truck as specified by MASH. Since the focus of this study was to solve the issue of vehicle under-riding, the evaluation of TMCMB-N-J under impacts by a pickup truck was not considered in the current work but should be conducted in the future.

\section{CONCLUSIONS}

In this study, finite element (FE) modelling and simulations were used to evaluate tiremounted cable median barriers (TMCMBs) to solve the issue of vehicle under-riding that was seen on the current cable barriers. Ten different material models were used in the FE models, including the piecewise linear plasticity model for most steel components, elastic model for the tires and a few other components, viscous damping model for the shock absorbers, low-density foam model for the radiator core, spot-weld model for sheet metal connections, Blatz-Ko rubber model for rubber cushions, rigid model for most mounting hardware, and null material model defined for contact purposes. Four different TMCMB designs were first evaluated when placed on a flat terrain and impacted by a small passenger car, i.e, a 1996 Dodge Neon. The best of the four designs evaluated, namely the TMCMB$\mathrm{N}-\mathrm{J}$ design, was then further evaluated on a $6 \mathrm{H}: 1 \mathrm{~V}$ sloped median, which was the most commonly used for cable barriers. The simulation results showed that the TMCMB design was effective for both front-side and backside impacts for two placements, one on the front slope and the other on the back slope. In the four cases evaluated, the TMCMB-N-J design was capable of redirecting the Dodge Neon and satisfy the requirements by Manual for Assessing Safety Hardware (MASH). This research provided valuable insights regarding the use of reclaimed tires on the current cable median barriers. For future investigations, the TMCMB-N-J design can be evaluated under impacts by a pickup truck based on MASH specifications to ensure its effectiveness before it can be used as a retrofit option for the current cable barrier systems.

\section{REFERENCES}

[1] Graham, M.D., Burnett, W.C., Gibson, J.L. \& Freer, R.H., New Highway Barriers: The Practical Application of Theoretical Design, Highway Research Record No. 174, 1967.

[2] Phillips, R., Tyrell, A., Bryden, J. \& Fortuniewicz, J., Cable guiderail breakaway terminal ends. Report FHWA/NY/RR-90/148, New York State Department of Transportation, Albany, NY, 1990.

[3] Laker, I.B. \& Naylor, A.W., Development and proving tests of a four-rope safety fence. Transportation Research Record, 1419, pp. 1-8, 1993.

[4] Yang, W., Bendana, L.J. \& Bruno, N.J., Performance of cable guiderail in New York. Transportation Research Record, 1419, pp. 9-20, 1993.

[5] Hunter, W.W., Stewart, J.R., Eccles, K.A., Huang, H.F., Council, F.M. \& Harkey, D.L., Three-strand cable median barrier in North Carolina in-service evaluation. Transportation Research Record, 1743(1), pp. 97-103, 1997.

[6] Sposito, B. \& Johnston, S., Three-cable median barrier. Report No. OR-RD-99-03, Oregon Department of Transportation, 1998.

[7] Cooner, S.A., Rathod, Y.K., Alberson, D.C., Bligh, R.P., Ranft, S.E. \& Sun, D., Performance evaluation of cable median barrier systems in Texas. Report No. FHWA/TX09/0-5609-1, US Department of Transportation, 2009.

[8] Stolle, C.S. \& Sicking, D.L., Impact conditions associated with cable median barrier failure. 93rd Annual Meeting of the Transportation Research Board, Paper No. 13-1564, 2013.

[9] Stolle, C.S., Factors contributing to cable median barrier penetrations. 93rd Annual Meeting of the Transportation Research Board, Paper No. 14-4624, 2014. 
[10] Burns, K. \& Bell, K., Performance evaluation of a cable median barrier system on an Oregon highway with a narrow median. Transportation Research Record, 2588, pp. 137144, 2016.

[11] Hiser, N.R. \& Reid, J.D., Modeling slip base mechanisms. International Journal of Crashworthiness, 10(5), pp. 463-472, 2005.

[12] Marzougui, D., Mohan, P., Kan, C. \& Opiela, K., Performance evaluation of low-tension three-strand cable median barriers. Transportation Research Record, 2025, pp. 34-44, 2007.

[13] Mohan, P., Marzougui, D., Meczkowski, L. \& Bedewi, N., Finite element modeling and validation of a 3-strand cable guardrail system. International Journal of Crashworthiness, 10(3), pp. 267-273, 2005.

[14] Fang, H., Wang, Q. \& Weggel, D.C., Crash analysis and evaluation of cable median barriers on sloped medians using an efficient finite element model. Advances in Engineering Software, 82, pp. 1-13, 2015.

[15] Fang, H., Li, N., DiSogra, M., Gutowski, M. \& Weggel, D.C., Recommendations for placement of cable median barriers on $6: 1$ and $4: 1$ sloped medians with horizontal curvatures. Report No. FHWA/NC/2011-09, North Carolina Department of Transportation, 2012.

[16] Stolle, C.S. \& Reid, J.D., Development of a wire rope model for cable guardrail simulation. International Journal of Crashworthiness, 16(3), pp. 331-341, 2011.

[17] Stolle, C.S., Reid, J.D. \& Bielenberg, R.W., Improved models of cable-to-post attachments for high-tension cable barriers. Report No. TRP-03-267-1212, Nebraska Department of Transportation, 2012.

[18] Wang, Q., Fang, H., Li, N., Weggel, D.C. \& Wen, G., An efficient FE model of slender members for crash analysis of cable barriers. Engineering Structures, 52, pp. 240-256, 2013.

[19] Walker, B., US Patent No. 3,661,359. US Patent and Trademark Office: Washington, DC, 1972.

[20] Way, M. \& Pas, J., US Patent No. 3,848,853. US Patent and Trademark Office: Washington, DC, 1974.

[21] Vincent, C.K., US Patent No. 4,090,694. US Patent and Trademark Office: Washington, DC, 1978.

[22] Yoho, L.E., US Patent No. 4,066,244. US Patent and Trademark Office: Washington, DC, 1978.

[23] Moon, D.G., US Patent No. 5,238,228. US Patent and Trademark Office: Washington, DC, 1993.

[24] Bernaquez, N. \& Sabourin, I., US Patent No. 5,480,255. US Patent and Trademark Office: Washington, DC, 1996.

[25] Yunick, H., US Patent No. 5,645,368. US Patent and Trademark Office: Washington, DC, 1997.

[26] Kramer, R., US Patent No. 20,030,081,997. US Patent and Trademark Office: Washington, DC, 2003.

[27] Diem, R., US Patent No. 6,505,993. US Patent and Trademark Office: Washington, DC, 2003.

[28] Talbott, A.F., US Patent No. 7,387,295. US Patent and Trademark Office: Washington, DC, 2008.

[29] MASH, Manual for Assessing Safety Hardware (MASH), American Association of State Highway and Transportation Officials (AASHTO): Washington, DC, 2009.

[30] LSTC, LS-DYNA Keyword User's Manual - Version 971, Livermore Software Technology Corporation (LSTC): Livermore, CA, 2007. 